\title{
Tropical Cyclone Contribution to Interdecadal Change in Summer Rainfall over South China in the Early 1990s
}

\author{
Joo-Hong Kim ${ }^{1, *}$, Chun-Chieh $\mathrm{Wu}^{1}$, Chung-Hsiung Sui ${ }^{1}$, and Chang-Hoi $\mathrm{Ho}^{2}$ \\ ${ }^{1}$ Department of Atmospheric Sciences, National Taiwan University, Taipei, Taiwan \\ ${ }^{2}$ School of Earth and Environmental Sciences, Seoul National University, Seoul, Korea
}

Received 7 April 2011, accepted 26 August 2011

\begin{abstract}
This study investigated the tropical cyclone (TC) rainfall $\left(P_{\mathrm{TC}}\right)$ contribution to the interdecadal change in summer (June, July and August) rainfall $\left(P_{\text {Total }}\right)$ over South China between 1981 - 1992 (ID1) and 1993 - 2002 (ID2). In an area-averaged sense, the interdecadal change in $P_{\text {Total }}$ was largely attributed to non-TC rainfall for the summer total and months of June and July, while $P_{\mathrm{TC}}$ became comparable in August. When the month-to-month spatial variability was considered, noticeable negative $P_{\mathrm{TC}}$ contributions showed up over the southeastern coast, Hainan Island, and Taiwan in June and over the southern coastal regions in July. In contrast, a positive $P_{\mathrm{TC}}$ contribution spread over South China with its maxima over the southern coastal regions in August, a pattern which appeared to be diametrically opposed to that of the negative $P_{\text {TC }}$ contribution in July, though the latter was less significant. The negative $P_{\text {TC }}$ contribution over the coastal and insular regions in June and July corresponded to less TC activity there. In June, it was attributed to reduced basin-wide TC activity due to prevailing unfavorable large-scale environments in ID2, whereas, in July, to less TC approaches from the Philippine Sea due to an enhanced cyclonic circulation centered on Taiwan in ID2. Conversely, in August, the overall enhanced positive $P_{\mathrm{TC}}$ contribution was mainly by the direct influences of increased TC formations over the South China Sea in ID2.
\end{abstract}

Key words: Summer rainfall, Tropical cyclone, Interdecadal change, South China

Citation: Kim, J. H., C. C. Wu, C. H. Sui, and C. H. Ho, 2012: Tropical cyclone contribution to interdecadal change in summer rainfall over South China in the early 1990s. Terr. Atmos. Ocean. Sci., 23, 49-58, doi: 10.3319/TAO.2011.08.26.01(A)

\section{INTRODUCTION}

Summer rainfall over China has shown salient interdecadal climate variability on top of interannual variability (Huang et al. 2004). A wetter middle and lower Yangtze River Valley and drier northern China characterized the interdecadal change in the Chinese summer rainfall from the late 1970s until the end of 1990s (Ho et al. 2005; Zhu et al. 2011). The interdecadal changes in the ocean and land lower boundary conditions, such as the Indo-Pacific sea surface temperatures (SSTs) (Chang et al. 2000; Gong and Ho 2002; Wu et al. 2010) and Tibetan Plateau snow cover (Chen and Wu 2000; Ding et al. 2009; Wu et al. 2010), have been suggested to be contributing factors for the interdecadal change in summer rainfall, by which the atmospheric large-scale environments (e.g., subtropical high) over East Asia and the western North Pacific (WNP) are modulated.

\footnotetext{
* Corresponding author

E-mail:jhkim@as.ntu.edu.tw
}

On the other hand, a strong decadal change of summer rainfall with a moderate increasing trend has been observed over South China (Qian and Qin 2008). An abrupt increase after the early 1990s (until the early 2000s) is considered to be a recent part of long-term climate variability. Wu et al. (2010) proposed an enhanced low-level convergence over South China sandwiched by two anomalous anticyclones to north (the North China-Mongolia anticyclone) and south [the South China Sea (SCS)-subtropical WNP anticyclone] as a plausible mechanism for a recently wetter South China. This large-scale mechanism involves the changes in ocean and land lower boundary conditions. The northern ChinaMongolia anticyclone is possibly related to increased Tibetan Plateau snow cover from the preceding winter to spring (e.g., Ding et al. 2009), while the SCS-subtropical WNP anticyclone is likely to be related to the increased SSTs in the equatorial Indian Ocean (e.g., Xie et al. 2009; Zhou et al. 2009). 
Kwon et al. (2007) also showed the increase in summer rainfall over South China in the early 1990s and attributed the significant decrease in the upper-tropospheric westerly jet over northern China (along $40^{\circ} \mathrm{N}$ ) to the upper-tropospheric divergent forcing arising from enhanced convection over South China. They found a noticeable increase in the number of tropical cyclones (TCs) passing around South China after the early 1990s and suggested that more frequent TC approaches are partly responsible for the increase in summer rainfall therein. Here two questions arise with respect to the quantitative contribution of TCs to the interdecadal change in the summer rainfall over South China. 1) Is the contribution of TCs to rainfall significant compared to the change due to the large-scale convergence? 2) While the contribution is expected to vary in time and space, what are the factors involved in month-to-month and regional variations? This study primarily aims to answer these two questions by separating TC-induced rainfall from total rainfall. The paper is organized as follows. Section 2 briefly describes the datasets used and the methodology. Results are presented in section 3 and finally summary and discussion are given in section 4 .

\section{DATA AND METHOD}

The daily rainfall records from weather stations across China and Taiwan are used to depict the interdecadal change in summer (June-July-August, JJA) rainfall during the early 1990s. The analysis period is confined to $1981-2005$ to highlight the recent interdecadal change. Following Wu et al. (2010), 1992/93 is selected as the division years between the early decade (ID1, 1981 - 1992) and the later decade (ID2, 1993 - 2002). The last three years (i.e., 2003, 2004, and 2005) are not included in ID2 because the rainfall over South China dropped significantly during those years (see Fig. 1a of Wu et al. 2010).

To demonstrate large-scale environments, we adopt the National Centers for Environmental Prediction (NCEP)/Department of Energy (DOE) Reanalysis 2 (R-2) (Kanamitsu et al. 2002). The NCEP/DOE R-2 is horizontally gridded in a $2.5^{\circ} \times 2.5^{\circ}$ resolution and is available from 1979 to the present. The 850 - and $200-\mathrm{hPa}$ horizontal winds, $600-\mathrm{hPa}$ relative humidity, and $500-\mathrm{hPa}$ geopotential height fields are retrieved from the NCEP/DOE R-2 source dataset. From the horizontal wind fields, the magnitude of vertical wind shear is driven by the formula $\sqrt{\left(\mathrm{U}_{200}-\mathrm{U}_{850}\right)^{2}+\left(\mathrm{V}_{200}-\mathrm{V}_{850}\right)^{2}}$, where $\mathrm{U}, \mathrm{V}$ and subscript denote zonal wind, meridional wind, and pressure level, respectively. Also, the monthly field of $850-\mathrm{hPa}$ eddy kinetic energy is derived by the formula $\left(\overline{\mathrm{U}_{850}^{\prime 2}+\mathrm{V}_{850}^{\prime 2}}\right) / 2$, where the prime and bar denote the synoptic component by subtracting a basic state defined (i.e., an 11-day running mean) from the daily data (Seiki and Takayabu 2007) and the monthly average, respectively.
The best-track records retrieved from the Regional Specialized Meteorological Centers Tokyo-Typhoon Center are used to locate the TC centers. An acceptable separation of TC-induced rainfall $\left(P_{\mathrm{TC}}\right)$ from rainfall induced by factors other than TCs (i.e., non-TC rainfall; $P_{\mathrm{NOTC}}$ ) is required for quantifying the contribution of TCs to the summer total rainfall. Thus far $P_{\mathrm{TC}}$ has been commonly defined by observed rainfall within the effective radius of a TC (e.g., Rodgers et al. 2000; Englehart and Douglas 2001; Ren et al. 2006; Kubota and Wang 2009; Chen et al. 2010; Jiang and Zipser 2010; Lee et al. 2010), so this study follows a simple approach to define $P_{\mathrm{TC}}$ based on the daily rainfall records and 6-hourly best track information. However, no consensus has been reached for the optimal value of the effective radius; rather, various values have been assumed to define $P_{\mathrm{TC}}$ in previous studies. Here, the distance is determined to be $550-\mathrm{km}$ from the TC center, which is the same as in the definition offered by Englehart and Douglas (2001), in which daily rainfall observed at a station is classified as $P_{\mathrm{TC}}$ when a TC is located within a $550-\mathrm{km}$ distance from the station. The monthly or seasonal $P_{\mathrm{TC}}$ is then produced by summing the daily $P_{\mathrm{TC}}$. The remaining amount of rainfall from the total rainfall $\left(P_{\text {Total }}\right)$ is classified as $P_{\text {NOTC }}$. It should be noted that general conclusions are insensitive to moderate changes in the effective radius of TC.

\section{RESULTS}

\subsection{Contributions of $\boldsymbol{P}_{\mathrm{TC}}$ vs. $\boldsymbol{P}_{\mathrm{NOTC}}$ to $\boldsymbol{P}_{\mathrm{Total}}$}

Before quantifying the TC contribution, the interdecadal changes (i.e., ID2 minus ID1) in $P_{\text {Total }}$ are displayed in Fig. 1 with respect to JJA and individual months (June, July, and August). Many weather stations (101 among 151 in the box) within the domains of South China exhibit a significant increase in seasonal $P_{\text {Total }}$ (Fig. 1a). This feature has been well recognized by some previous studies (Kwon et al. 2007; Yao et al. 2008; Wu et al. 2010). Monthly changes also show an overall increase over South China, indicating that all months contribute constructively to the seasonal mean pattern of the interdecadal change over South China (Figs. 1b - d), though a close examination may emphasize month-to-month variability in locations where the interdecadal change is significant.

Figures 2 and 3 present the analysis results that quantify the TC contribution $\left(P_{\mathrm{TC}}\right)$ and non-TC contribution $\left(P_{\text {NOTC }}\right)$ to the interdecadal change around 1992/93 and show that the TC generally contributes positively to the seasonal mean $P_{\text {Total }}$ over the large domain of South China (Fig. 2a). Compared to the seasonal mean interdecadal change in $P_{\text {Total }}$ (Fig. 1a), however, its magnitudes in terms of $P_{\mathrm{TC}}$ are much smaller and mostly insignificant with values less than $25 \mathrm{~mm} \mathrm{mon}^{-1}$. The minor TC contribution to the interdecadal change leads a pattern of the interdecadal change in $P_{\text {NOTC }}$ to nearly congruent with that in $P_{\text {Total }}$ 
(a)

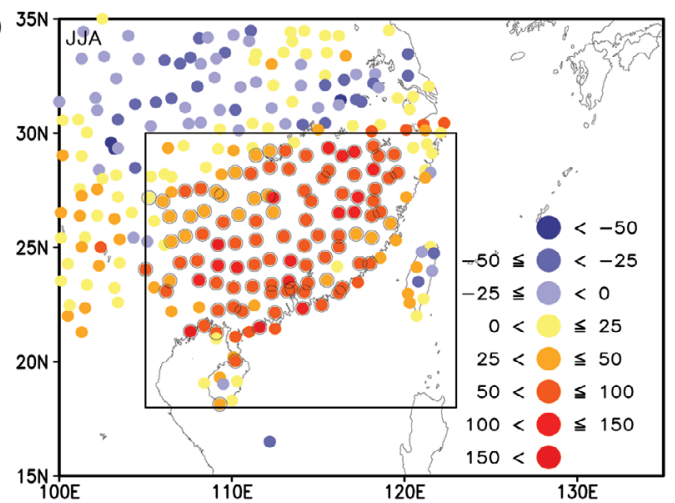

(c)

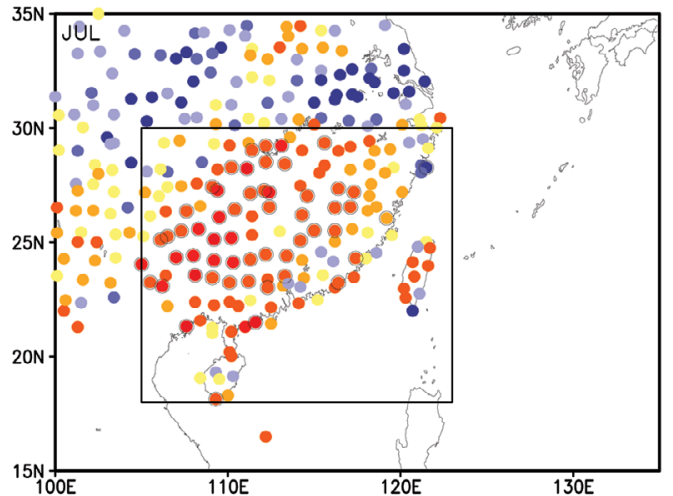

(b)

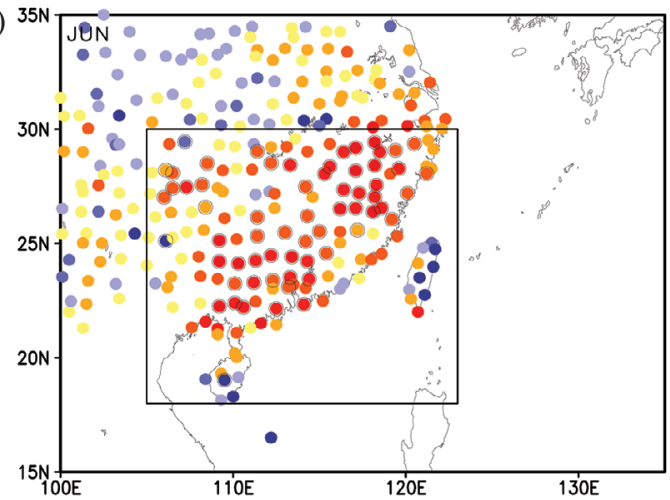

(d)

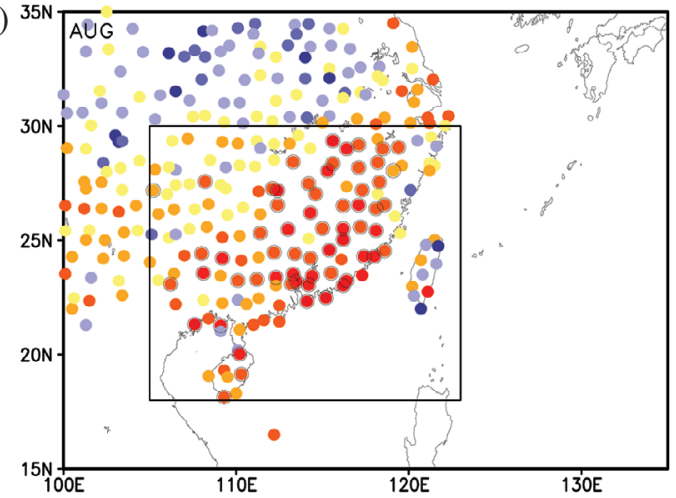

Fig. 1. The difference of total rainfall $\left(P_{\text {Total }}\right.$, unit: $\left.\mathrm{mm} \mathrm{mon}^{-1}\right)$ in JJA (a), June (b), July (c), and August (d) between the period ID2 and ID1. The lined circles denote the stations over South China (box; $18-30^{\circ} \mathrm{N}, 105-123^{\circ} \mathrm{E}$ ) where the decadal change is statistically significant at the $90 \%$ confidence level using the two-sided $t$-test.

(a)

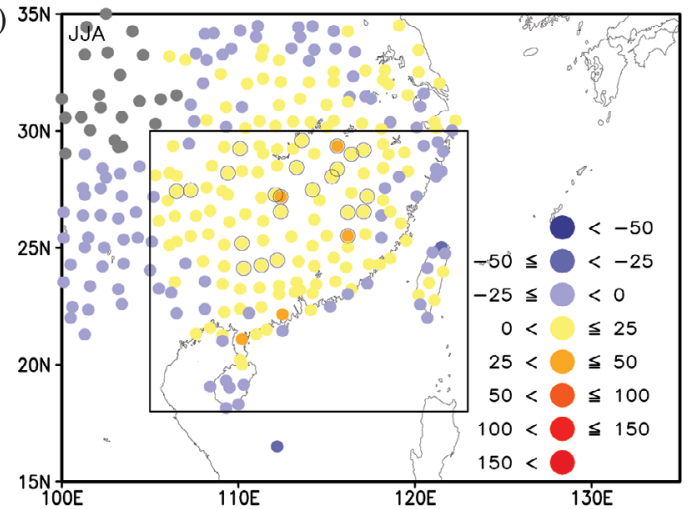

(c)

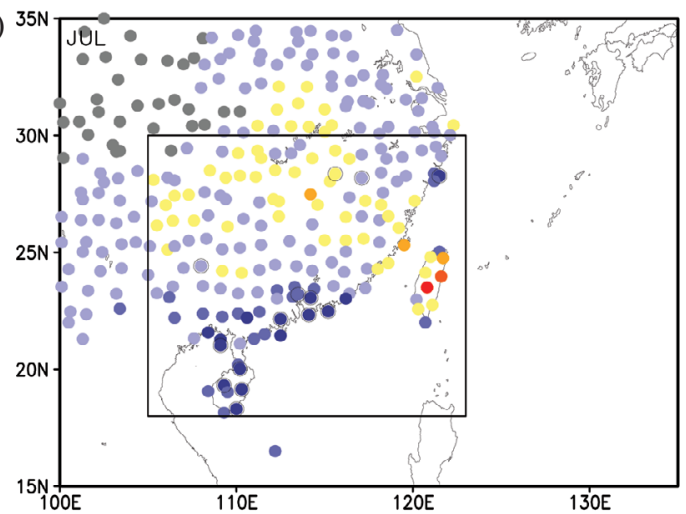

(b)

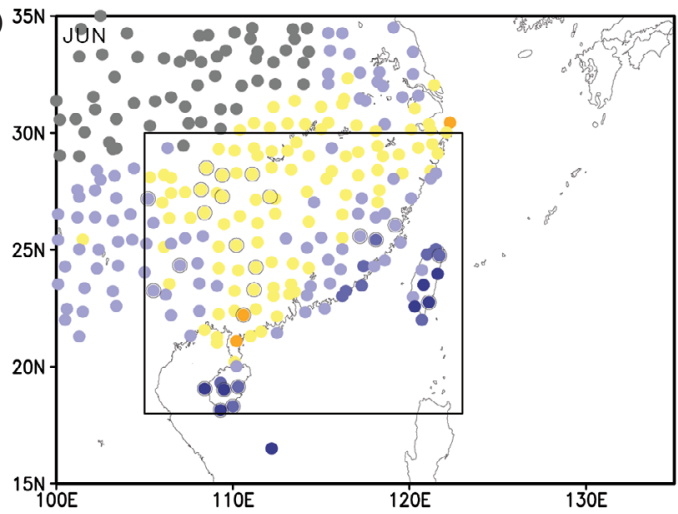

(d)

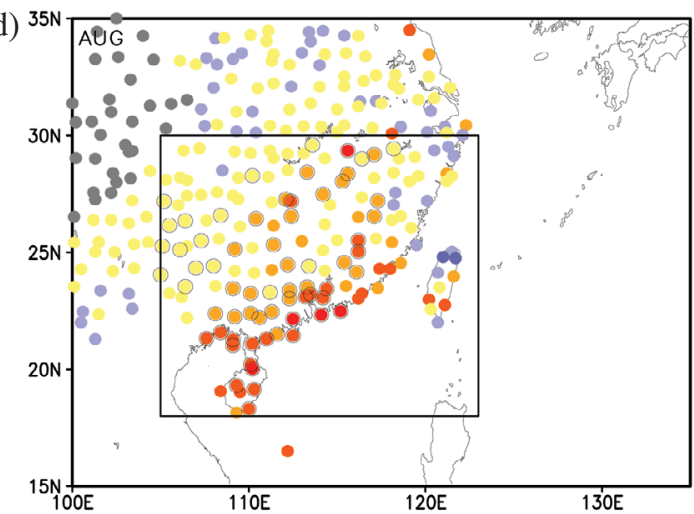

Fig. 2. Same as Fig. 1 except that it is for TC-induced rainfall $\left(P_{\mathrm{TC}}\right)$. The gray circles denote the stations where $P_{\mathrm{TC}}$ is not available. 
(a)

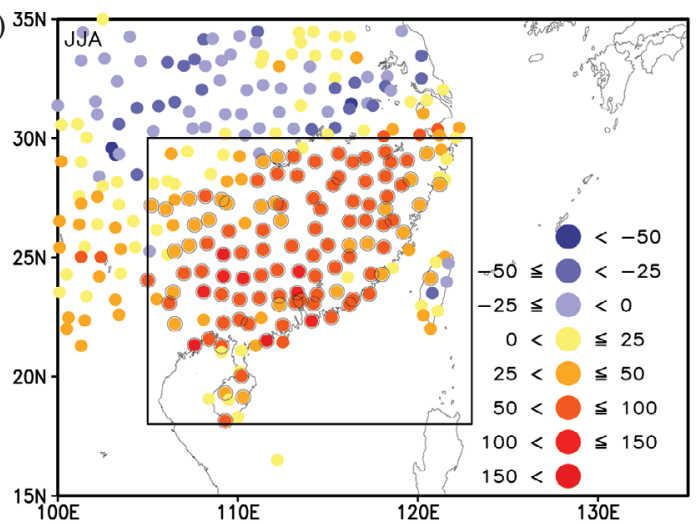

(c)

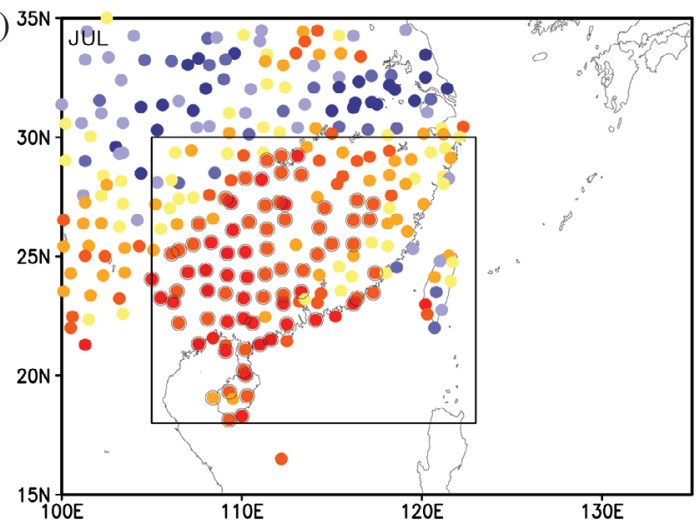

(b)

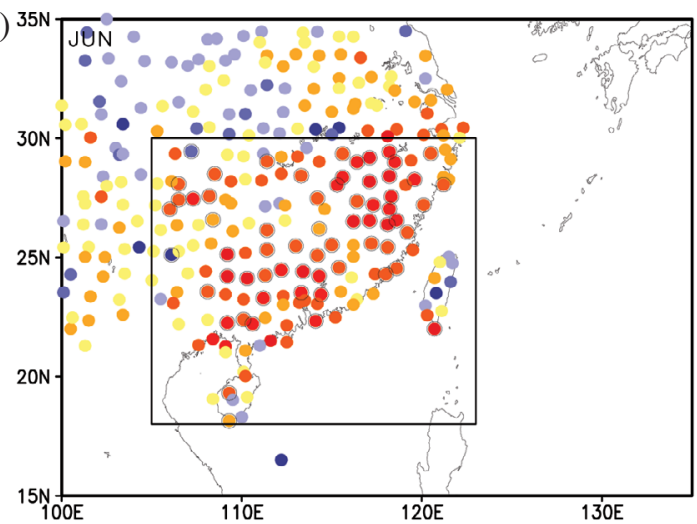

(d)

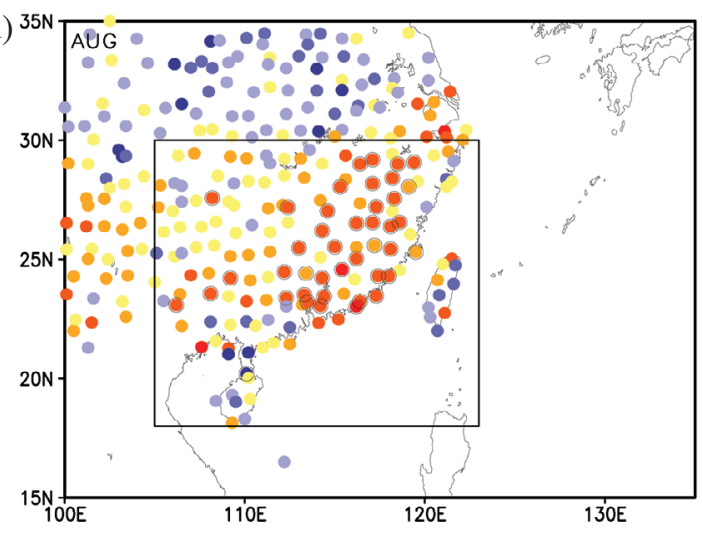

Fig. 3. Same as Fig. 1 except that it is for non-TC-induced rainfall ( $\left.P_{\text {NOTC }}\right)$.

(Fig. 3a). This result favors the conclusion that enhanced large-scale convergence in ID2 is a dominant cause of the interdecadal change in the seasonal mean rainfall (Wu et al. 2010).

Although the TC contribution is found to be minor in the seasonal mean sense, its discernible substantial monthto-month variability is noteworthy (Figs. $2 b-d$ ). Taking the seasonal variation of TC activity into account, naturally we could expect month-to-month variability to occur. However, the factors involved in the monthly TC contribution to the interdecadal change in $P_{\text {Total }}$ remain unknown. In June, the $P_{\mathrm{TC}}$ change is generally weak within the mainland, but comparable to the $P_{\text {Total }}$ change in some stations at Hainan Island and Taiwan. Thus, the $P_{\text {Total }}$ change in June is more or less similar to the $P_{\mathrm{TC}}$ change in those regions (Fig. 2b vs. 1b), while it is dominated by the $P_{\text {NOTC }}$ on the mainland (Fig. 3b vs. 1b). Here the presence of the domain of weakly positive $P_{\mathrm{TC}}$ changes inland except in the southeastern coastal region seems to be questionable in the sense that the negative $P_{\mathrm{TC}}$ changes appeared over the coastal stations where the TC influence is more rigorous (Fig. 3b). To unveil this equivocal change in June, we analyzed the time series of $P_{\mathrm{TC}}$ at some stations showing significant negative and positive changes (figure not shown). As expected, the amount of $P_{\mathrm{TC}}$ had decreased in ID2 over the stations in Hainan Island. Interestingly, however, much larger $P_{\mathrm{TC}}$ over the inland stations to the north of Hainan Island is found in the month of June for 1993, 1994, and 1999 in ID2, during which four TCs (e.g., KORYN in 1993, RUSS and SHARON in 1994, and MAGGIE in 1999) made landfall over Guangdong Province. The weakly positive $P_{\text {TC }}$ changes inland were attributed to much heavier $P_{\mathrm{TC}}$ by the only four TCs, even though the remaining years showed almost zero $P_{\mathrm{TC}}$ in June therein. Therefore, the weakly positive $P_{\mathrm{TC}}$ change inland is probable, even though the strongly negative change appeared in the coastal regions (Fig. 3b).

The interdecadal changes in $P_{\mathrm{TC}}$ in July and August are in striking contrast to each other: i.e., in July, a large $P_{\mathrm{TC}}$ reduction is observed in some stations in Guangdong Province and Hainan Island (Fig. 2c) while a change in the opposite direction is observed in August (Fig. 2d). It is conceivable that the reversed trend in the southern coastal regions between July and August leads to the trivial TC contribution to the interdecadal change in JJA. Meanwhile, in August, quite a few inland stations show statistically significant increases in ID2. All of these results not only indicate that the interdecadal change in TC activity over South China is distinct between July and August, which will be demonstrated later, but also suggest that the contribution of $P_{\mathrm{TC}}$ to the interdecadal change in $P_{\text {Total }}$ is comparable to or even larger than that of $P_{\text {NOTC }}$ at least in the southern coastal regions of South China on a sub-seasonal time scale. Naturally, some 
notable differences in the pattern of the interdecadal change between $P_{\text {Total }}$ and $P_{\text {NOTC }}$ can be expected around the regions where considerable TC contribution is found. In July, in compensation for the large decrease in $P_{\mathrm{TC}}$, the interdecadal change in $P_{\text {NOTC }}$ becomes significant at southern coastal stations in Guangdong Province and Hainan Island (Fig. 3c), where $P_{\text {Total }}$ is not significant (Fig. 1c). The number of stations with a significant change increases from 55 for $P_{\text {Total }}$ to 74 for $P_{\text {NOTC }}$ in July. In August, on the contrary, the number of significant stations decreases from 61 for $P_{\text {Total }}$ to 42 for $P_{\text {NOTC }}$ (Fig. 3d vs. 1d), which is attributed to the substantial positive contribution of $P_{\mathrm{TC}}$ to the interdecadal change in $P_{\text {Total }}$ (Fig. 2d).

In addition to the interdecadal difference, the mean quantities of rainfall are listed in Table 1. To homogenize the effects of each rainfall-type (i.e., $P_{\text {Total }}, P_{\mathrm{TC}}$, and $P_{\text {NOTC }}$ ) on the South China domain regardless of the month-tomonth variability, the area-average is performed for the 151 stations over South China (the box in Fig. 1). The climatological seasonal mean $P_{\text {Total }}$ over South China is 219.7 $\mathrm{mm} \mathrm{mon}{ }^{-1}$ for the entire period (1981 - 2005), about $85 \%$ of which $\left(187.7 \mathrm{~mm} \mathrm{mon}^{-1}\right)$ comes from $P_{\mathrm{NOTC}}$, indicating the $P_{\mathrm{TC}}$ contribution is minor. In case of dividing the seasons into individual months, the $P_{\mathrm{TC}}$ contribution continuously increases from $14.8 \mathrm{~mm} \mathrm{mon}^{-1}(5.8 \%)$ in June to $45.8 \mathrm{~mm} \mathrm{mon}^{-1}(23.4 \%)$ in August. Clearly, the $P_{\text {NOTC }}$ contribution dominates $P_{\text {Total }}$ over South China during the summer season (as in Fig. 3a). This statement is not only valid for the mean rainfall with respect to the two sub-periods

Table 1 . The area-averaged $P_{\text {Total }}, P_{\mathrm{TC}}$, and $P_{\mathrm{NOTC}}$ in JJA, June, July and August for period ID1 (third column), ID2 (fourth column), and 1981 - 2005 (fifth column). A total of 151 stations over South China is used for the area-average.

\begin{tabular}{|c|c|c|c|c|}
\hline & $\mathbf{m m} \mathbf{m o n}^{-1}$ & $\begin{array}{l}1981 \text { - } 1992 \\
\text { (ID1) }\end{array}$ & $\begin{array}{l}1993 \text { - } 2002 \\
\quad \text { (ID2) }\end{array}$ & $1981-2005$ \\
\hline \multirow{3}{*}{ JJA } & $P_{\text {Total }}$ & 196.7 & $253.5^{* * *}$ & 219.7 \\
\hline & $P_{\mathrm{TC}}$ & 29.8 & 34.2 & 32.0 \\
\hline & $P_{\text {NOTC }}$ & 166.9 & $219.3^{* * *}$ & 187.7 \\
\hline \multirow{3}{*}{ JUN } & $P_{\text {Total }}$ & 231.2 & $290.3^{* *}$ & 256.5 \\
\hline & $P_{\mathrm{TC}}$ & 18.5 & 14.3 & 14.8 \\
\hline & $P_{\text {NOTC }}$ & 212.7 & $276.0^{* *}$ & 241.7 \\
\hline \multirow{3}{*}{ JUL } & $P_{\text {Total }}$ & 185.6 & $240.3^{* *}$ & 206.5 \\
\hline & $P_{\mathrm{TC}}$ & 39.8 & 28.6 & 35.5 \\
\hline & $P_{\text {NOTC }}$ & 145.8 & $211.7^{* * *}$ & 171.0 \\
\hline \multirow{3}{*}{ AUG } & $P_{\text {Total }}$ & 173.1 & $229.9^{* *}$ & 196.1 \\
\hline & $P_{\mathrm{TC}}$ & 31.0 & $59.5^{*}$ & 45.8 \\
\hline & $P_{\text {NOTC }}$ & 142.1 & 170.4 & 150.3 \\
\hline
\end{tabular}

Note: ${ }^{*} 95 \%,{ }^{* *} 99 \%,{ }^{* * *} 99.9 \%$ (i.e., ID1 and ID2), but also for the interdecadal changes in JJA, June, and July. However, the $P_{\mathrm{TC}}$ contribution to the interdecadal change in August becomes comparable to that of $P_{\text {NotC }}\left(28.5\right.$ vs. $\left.28.3 \mathrm{~mm} \mathrm{mon}^{-1}\right)$. Moreover, the interdecadal change in $P_{\mathrm{TC}}$ becomes statistically significant, while that in $P_{\text {NOTC }}$ is not. This indicates that in August, TC activity becomes an important contributor to the interdecadal change in $P_{\text {Total }}$ around $1992 / 93$.

\subsection{Monthly TC Activity and Large-Scale Environments}

Figure 4 demonstrates the monthly TC tracks in ID1 and ID2 separately. In the plot, the TCs that induced rainfall at any South China stations are displayed with colored tracks. It is noted that some TCs that formed in the previous month are included in the number count of the target month if they induced rainfall over South China in the target month. The frequency of TC formations was reduced in June of ID2 (from 2.3 to $1.3 \mathrm{yr}^{-1}$ ), resulting in a weaker TC influence (from 1.8 to $0.9 \mathrm{yr}^{-1}$ ) on South China, provided that the percentage of TCs affecting South China is almost conserved (75\% vs. 69\%). Its influence on the rainfall decrease is especially noticeable over Hainan Island and Taiwan (Fig. 2b). In July, the yearly number of TC formations somewhat increased in ID2, while that of TCs affecting South China slightly dropped at the same time, resulting in the decrease in percentage (from $71 \%$ to $53 \%$ ). While the frequency of TC formations over the SCS went up slightly to $1.2 \mathrm{yr}^{-1}$ from $0.83 \mathrm{yr}^{-1}$, the TC approaches from the Philippine Sea largely decreased from $24\left(2.0 \mathrm{yr}^{-1}\right)$ to 12 $\left(1.2 \mathrm{yr}^{-1}\right)$. The latter is the primary cause of the slightly reduced $P_{\mathrm{TC}}$ over South China in ID2 (Table 1), by which Guangdong Province and Hainan Island were most affected (Fig. 2c). In contrast, the frequency of TCs affecting South China has increased from 2.9 to $4.0 \mathrm{yr}^{-1}$ in August, though the total frequency of formations did not change much $(6.3$ vs. $\left.6.6 \mathrm{yr}^{-1}\right)$. A remarkable change is observed over the SCS, where the formation frequency has risen to $16\left(1.6 \mathrm{yr}^{-1}\right)$ from $9\left(0.8 \mathrm{yr}^{-1}\right)$. Therefore, the substantial increase in $P_{\mathrm{TC}}$ in August (Fig. 2d and Table 1) is mostly attributed to this enhanced TC formation in ID2 over the SCS.

To physically interpret the month-to-month difference in TC activity, the interdecadal changes in relevant largescale environments are presented in Fig. 5 with respect to each month. The large-scale environments include the $500-\mathrm{hPa}$ geopotential height and the magnitude of vertical wind shear (Fig. 5a), the horizontal wind and eddy kinetic energy at $850 \mathrm{hPa}$ (Fig. 5b), and the $600-\mathrm{hPa}$ relative humidity (Fig. 5c). All of these fields are typically regarded to be pertinent to the interpretation of climate variability of TC activity (e.g., Ho et al. 2004; Camargo et al. 2007; Kim et al. 2010; Zhan et al. 2011; and many others).

The overall diminished TC activity in June of ID2 (Fig. 4a vs. b) can be expected in that there prevail a large 
anomalous anticyclone in the low and middle troposphere, low-level negative eddy kinetic energy anomalies, and reduced mid-tropospheric humidity in the subtropics (top panels of Fig. 5). Compared to June of ID1, both dynamic and thermodynamic conditions were less favorable for the TC development in June of ID2. In July, on the other hand, fewer westward moving TCs were observed in ID2 than in ID1 (Fig. 4c vs. d). This is found to be ascribed to the negative anomalies of the 500-hPa geopotential height and the anomalous cyclone centered on Taiwan (Figs. 5a and b). The weaker easterly steering flows in July of ID2 west of $140^{\circ} \mathrm{E}$ between 15 and $20^{\circ} \mathrm{N}$, which are represented by the anomalous westerlies therein (Fig. 5b), guided the TCs developed over the Philippine Sea toward the mid-latitude. At the same time, the low-level eddy kinetic energy poleward of $20^{\circ} \mathrm{N}$ between 120 and $150^{\circ} \mathrm{E}$ increased in July of ID2. This enhanced synoptic activity toward the mid-latitude is likely to be partly attributed to the more recurving TCs in (a)

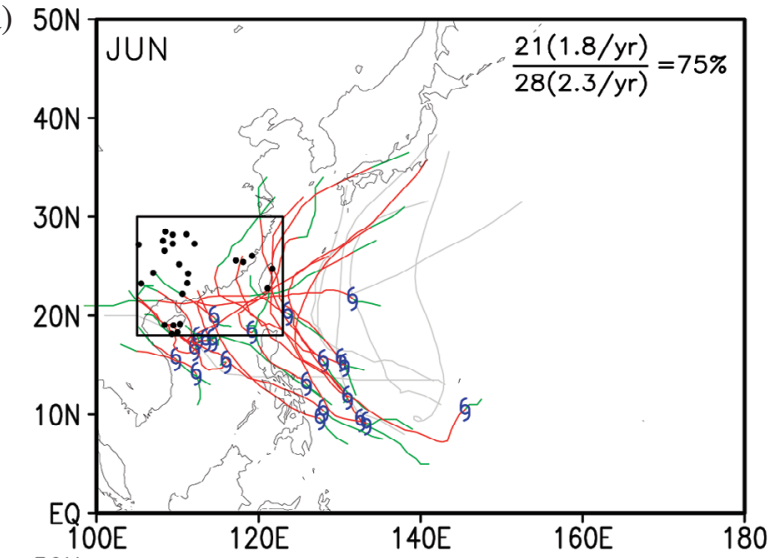

(c)

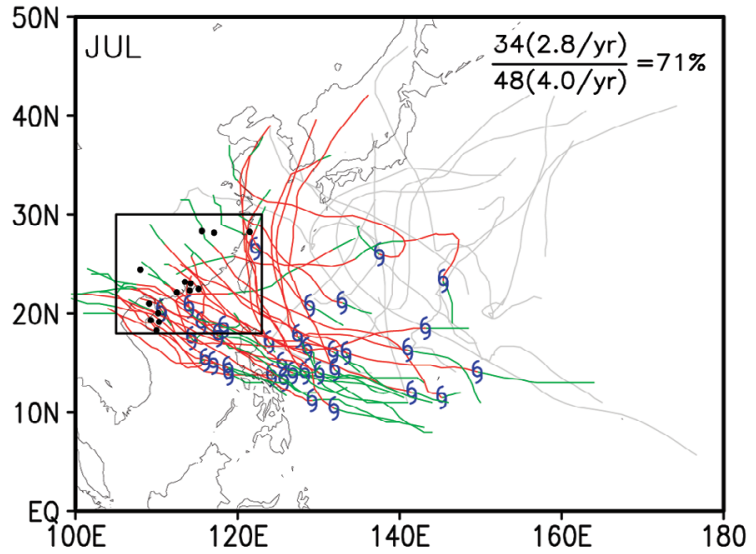

(e)

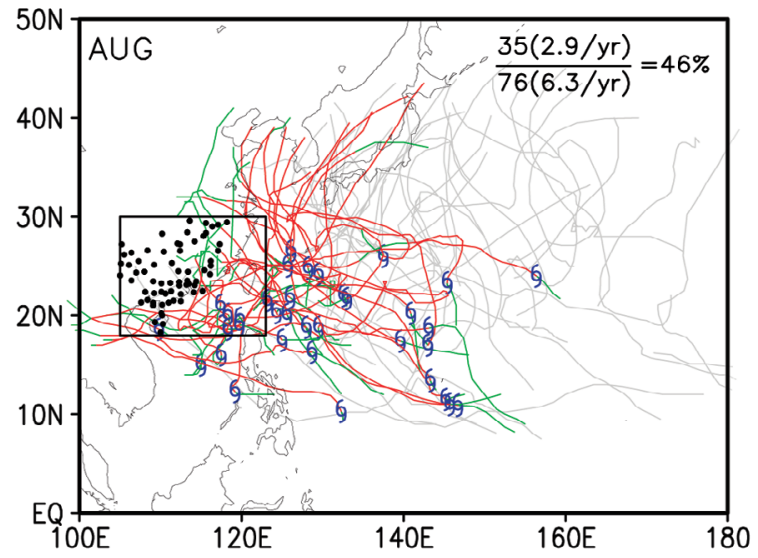

(b)

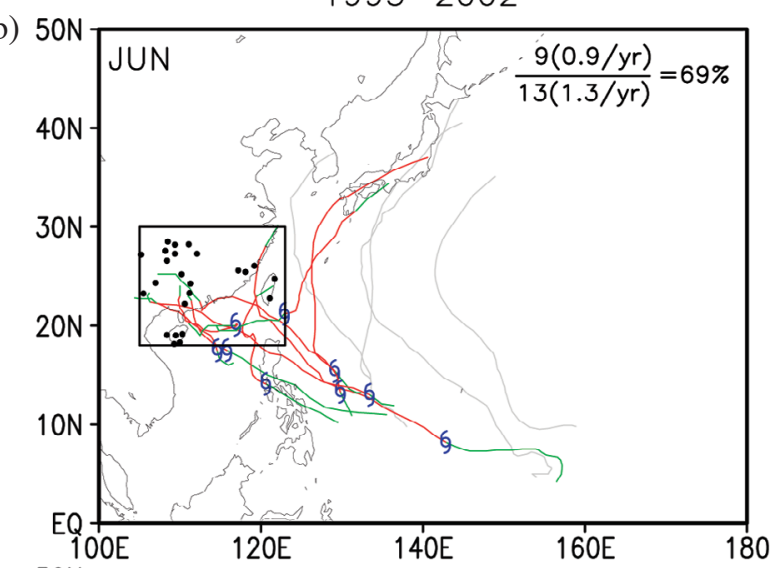

(d)

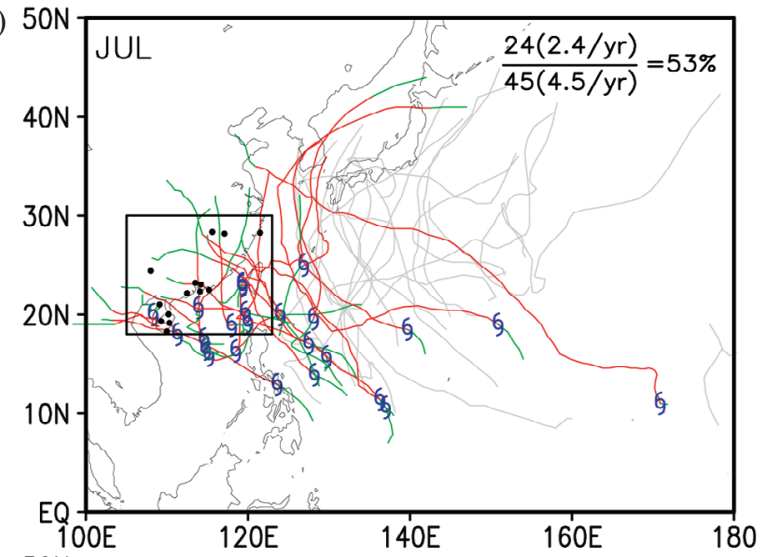

(f)

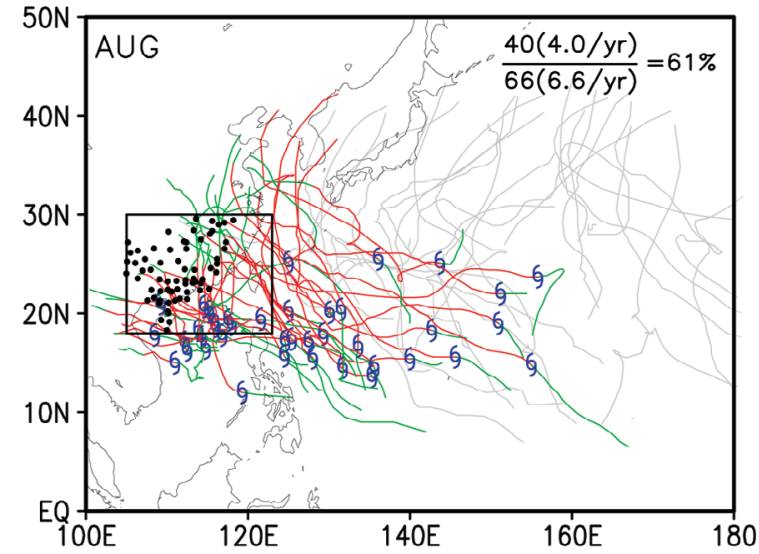

Fig. 4. The TC tracks in June (a) - (b), July (c) - (d), and August (e) - (f) for period ID1 (left) and ID2 (right). The TCs which induced rainfall over South China are plotted with red (tropical storm stage) and green (tropical depression stage) colors and their starting locations are shown (blue storm symbols). Black dots indicate the stations with a significant interdecadal change in $P_{\mathrm{TC}}$ for each month (from Fig. 2). The numerator in the fraction is the number of TCs that induced rainfall over South China, while the denominator is the total number formed over the western North Pacific. 
(a) H50O \& Mag. VWS
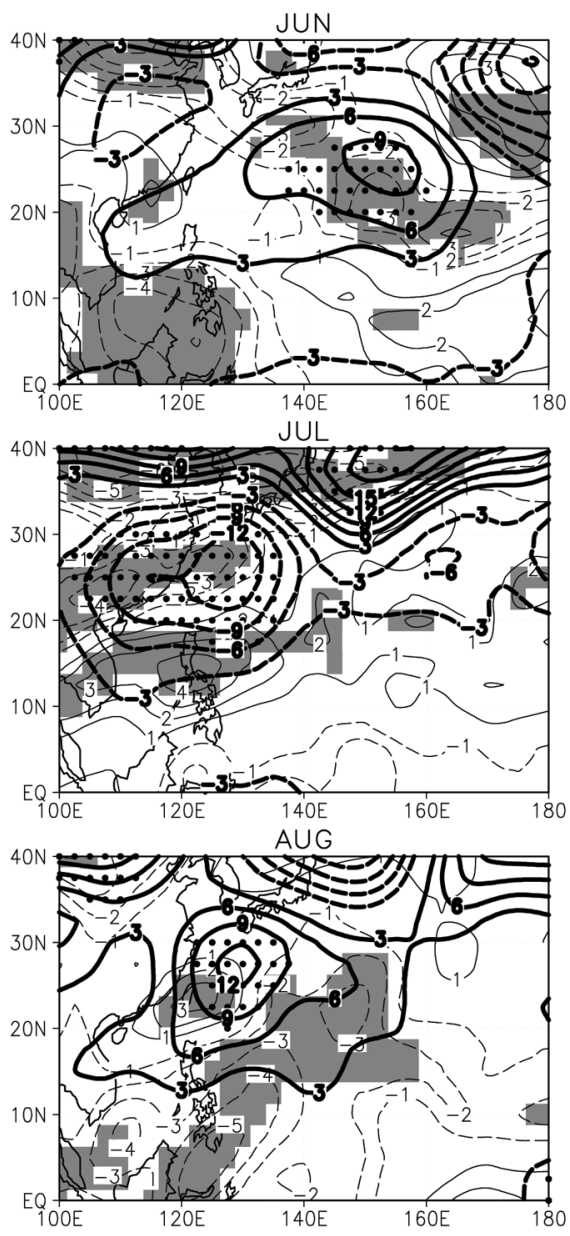

(b) UV850 \& EKE850

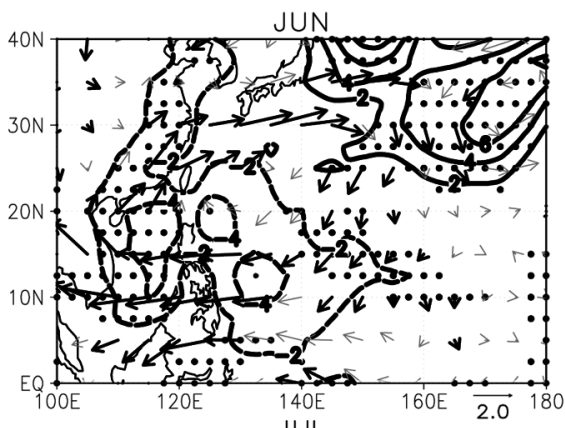

JUL
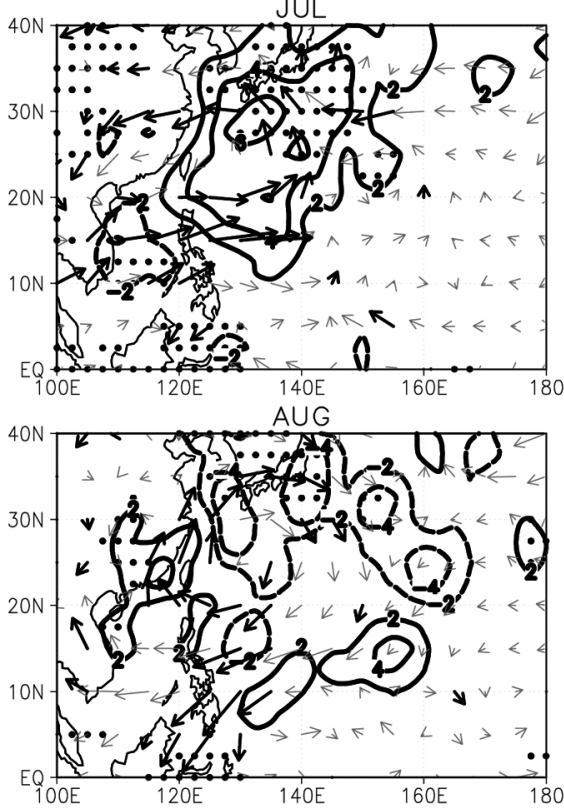

(c) $\mathrm{RH} 600$
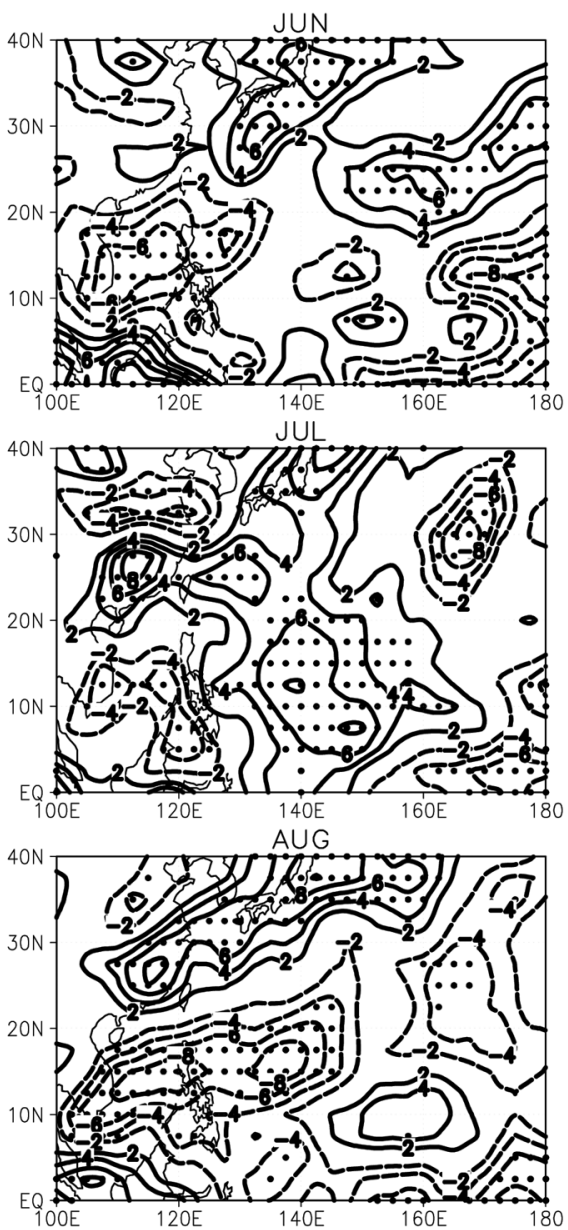

Fig. 5. The difference of 500-hPa geopotential height (thick contour, unit: gpm) and magnitude of vertical wind shear (thin contour, unit: $\mathrm{m} \mathrm{s} \mathrm{s}^{-1}$ ) (a), 850-hPa horizontal wind (vector, unit: $\mathrm{m} \mathrm{s}^{-1}$ ) and eddy kinetic energy (thick contour, unit: $\mathrm{m}^{2} \mathrm{~s}^{-2}$ ) (b), and 600-hPa relative humidity (unit: \%) (c) between period ID2 and ID1 for June (top), July (middle), and August (bottom). The dots indicate the grids where the decadal changes in 500-hPa geopotential height, $850-\mathrm{hPa}$ eddy kinetic energy, and 600-hPa relative humidity are statistically significant at the $90 \%$ confidence level using the two-sided t-test, while the shadings and the black vectors denote the grids where the magnitude of vertical wind shear and 850-hPa horizontal wind are significant, respectively. Zero contours are omitted for simplicity.

July of ID2 as observed in Fig. 4d. Meanwhile, the interdecadal change in mid-tropospheric humidity in July shows an increase over a large area of the WNP (Fig. 5c), while the magnitude of vertical wind shear also shows a positive change from the SCS toward the subtropical Philippine Sea (Fig. 5a). The latter may act to offset the favorable effect of the former, resulting in similar frequency of TC genesis in July of the both decades.

In August (bottom panels), the overall patterns of the interdecadal change look opposite to those in July to some extent. In contrast to July, a favorable dynamic condition for the TC development formed in the tropical WNP in the context of the weaker magnitude of vertical wind shear (Fig. 5a), whereas the mid-tropospheric humidity has decreased disfavoring the TC development (Fig. 5c). This possible offsetting effect seemed to operate to maintain the monthly number of TCs per year from ID1 through ID2 in
August similar to July. In fact, the characteristic feature in August was the increased formation over the SCS from 9 in ID1 to 16 in ID2. However, it is difficult to find any relevant large-scale environmental changes favoring the TC development over the SCS. Although the low-level eddy kinetic energy field shows a positive change along the coast of South China (Fig. 5b), it does not look to be a favorable condition for the TC development, but to be the result of enhanced TC activity over the SCS.

In addition to the interpretations relevant to TC activity, the persistent positive interdecadal changes in mid-tropospheric humidity (Fig. 5c) may be a clue of why $P_{\text {NOTC }}$ over South China had increased in ID2 for the entire summer months (Fig. 3). To demonstrate it more clearly, we checked the low-level moisture flux and its divergence around South China (figure not shown). Clearly found is the prevalence of the moisture convergence toward South 
China spanning for the whole summer months, despite of the significant month-to-month variability in large-scale circulation changes (Figs. 5a and b). This is consistent with the previous results (Qian and Qin 2008; Wu et al. 2010).

\section{SUMMARY AND DISCUSSION}

Thus far we have examined the TC contribution to summer rainfall over South China to seek the answers to the two questions raised above. The climatological contribution of $P_{\mathrm{TC}}$ to the area-averaged $P_{\text {Total }}$ was relatively small compared to that of $P_{\text {NOTC. }}$. In consequence, the contribution of $P_{\mathrm{TC}}$ to the interdecadal change in $P_{\text {Total }}$ over South China around 1992/93 was also found to be minor in general, which led to the conclusion that the large-scale convergence into the South China region is the dominant factor leading to enhanced summer rainfall in ID2 as discussed by Wu et al. (2010). However, an exceptional case was found in August, which agreed with both our expectations for substantial month-to-month variability and that derived from Kwon et al. (2007). The TC contribution to the August interdecadal change in area-averaged $P_{\text {Total }}$ was revealed to be about $50 \%$, even though the total area-averaged amount of $P_{\mathrm{TC}}$ was still less by a factor of 3 than that of $P_{\mathrm{NOTC}}$ even in ID 2 when $P_{\mathrm{TC}}$ increased significantly.

Furthermore, the sub-regional heterogeneities among the individual months were revealed in the $P_{\mathrm{TC}}$ contribution to the interdecadal change in $P_{\text {Total }}$ if the spatial variability were concerned, which originated from the distinct monthto-month contrast of the interdecadal change in TC activity. In June, basin-wide TC activity was much quiescent in ID2, resulting in less TC activity over South China, but the signals in rainfall relevant to such reduced TC activity were only found over island regions. The contrast between July and August was noticeable in both $P_{\mathrm{TC}}$ and TC activity. In July, a regional decrease in $P_{\mathrm{TC}}$ around Guangdong Province and Hainan Island was observed corresponding to less frequent approaches of TCs from the east of the Philippines due to fewer formations there in ID2. In August, however, a $P_{\mathrm{TC}}$ increase in ID2 became an important factor for the interdecadal change in $P_{\text {Total }}$ corresponding to more frequent formations over the SCS.

The characteristic interdecadal changes in TC activity for the individual months are partly reflected in some monthly mean large-scale fields with clear month-to-month differences. In June, the tropical WNP became much less convective (i.e., in drier and anticyclonic conditions) in ID2, which well matches with the suppressed TC activity. On the other hand, the weakened subtropical high north of the main development region was the characteristic large-scale feature in July of ID2 compared to ID1, which indicates weaker steering easterlies along the southern periphery of the subtropical high and, in turn, fewer straight-moving TCs over the Philippine Sea in ID2. The characteristic feature in August is the offsetting effect between the magnitude of vertical wind shear and the mid-tropospheric humidity, which seemed to maintain the monthly number of TCs per year from ID1 through ID2. In addition, the low-level synoptic activity was enhanced along the coast of South China, which seemed to result from the enhanced TC activity over the SCS.

Although the possible factors for the interdecadal changes in TC activity are listed separately for individual months, the causes of month-to-month variability in the interdecadal change in TC activity were not thoroughly investigated because this issue is not within the primary scope of this study. As a further step, the sub-seasonal variation needs to be investigated to understand why the interdecadal changes in TC activity for the individual months were manifested by different large-scale factors. Of course, this requires improved understanding of the sub-seasonal variation of the prevailing large-scale mechanisms of TC formation over the WNP.

Meanwhile, if the less frequent formation over the Philippine Sea in July of ID2 and the more frequent formation over the SCS in August of ID2 were combined, the timing of the interdecadal change would agree well with that of the dipolar redistribution of TC genesis in July-August-September between the SCS and the Philippine Sea, even though such a combination leaves out data in September (Kim et al. 2010). In other words, the interdecadal variability of the dipolar redistribution of seasonal TC genesis between the two seas can be interpreted, at least during the analysis period of this study, with a combination of the different variations among the individual months. This naturally demands further study on the combined characteristics of the interdecadal variability in regional TC activity and rainfall on both seasonal and sub-seasonal time scales.

Acknowledgements This work was funded by the National Science Council of Taiwan Grants NSC98-2111M-002-008-MY3 and NSC99-2811-M-002-076. C. H. Sui was funded by NSC98-2745-M-002-001-ASP. C. H. Ho was funded by the Korea Meteorological Administration Research and Development Program under the grant CATER 2006-4204. J. H. Kim is grateful to Min-Hee Lee for providing her prototype programs to class the rainfall data. The authors also thank two anonymous reviewers for their helpful comments.

\section{REFERENCES}

Camargo, S. J., K. A. Emanuel, and A. H. Sobel, 2007: Use of a genesis potential index to diagnose ENSO effects on tropical cyclone genesis. J. Climate, 20, 4819-4834, doi: 10.1175/JCLI4282.1. [Link]

Chang, C. P., Y. Zhang, and T. Li, 2000: Interannual and interdecadal variations of the East Asian summer mon- 
soon and tropical Pacific SSTs. Part I: Roles of the subtropical ridge. J. Climate, 13, 4310-4325, doi: 10.11 75/1520-0442(2000)013<4310:IAIVOT>2.0.CO;2. [Link]

Chen, J. M., T. Li, and C. F. Shih, 2010: Tropical cycloneand monsoon-induced rainfall variability in Taiwan. J. Climate, 23, 4107-4120, doi: 10.1175/2010JCLI33 55.1. [Link]

Chen, L. and R. Wu, 2000: Interannual and decadal variations of snow cover over Qinghai-Xizang Plateau and their relationships to summer monsoon rainfall in China. Adv. Atmos. Sci., 17, 18-30, doi: 10.1007/s00376-0 00-0040-7. [Link]

Ding, Y., Y. Sun, Z. Wang, Y. Zhu, and Y. Song, 2009: Inter-decadal variation of the summer precipitation in China and its association with decreasing Asian summer monsoon Part II: Possible causes. Int. J. Climatol., 29, 1926-1944, doi: 10.1002/joc.1759. [Link]

Englehart, P. J. and A. V. Douglas, 2001: The role of eastern North Pacific tropical storms in the rainfall climatology of western Mexico. Int.J. Climatol., 21, 1357-1370, doi: 10.1002/joc.637. [Link]

Gong, D. Y. and C. H. Ho, 2002: Shift in the summer rainfall over the Yangtze River valley in the late 1970s. Geophys. Res. Lett., 29, 1436, doi: 10.1029/2001GL01 4523. [Link]

Ho, C. H., J. J. Baik, J. H. Kim, D. Y. Gong, and C. H. Sui, 2004: Interdecadal changes in summertime typhoon tracks. J. Climate, 17, 1767-1776, doi: 10.1175/1520-0 442(2004)017<1767:ICISTT>2.0.CO;2. [Link]

Ho, C. H., J. H. Kim, K. M. Lau, K. M. Kim, D. Gong, and Y. B. Lee, 2005: Interdecadal changes in heavy rainfall in China during the northern summer. Terr. Atmos. Ocean. Sci., 16, 1163-1176.

Huang, R., G. Huang, and Z. Wei, 2004: Climate variations of the summer monsoon over China. In: Chang, C. P. (Ed.), East Asian Monsoon, World Scientific Publishing Co. Pte. Ltd., Singapore, 213-268.

Jiang, H. and E. J. Zipser, 2010: Contribution of tropical cyclones to the global precipitation from eight seasons of TRMM data: Regional, seasonal, and interannual variations. J. Climate, 23, 1526-1543, doi: 10.1175/20 09JCLI3303.1. [Link]

Kanamitsu, M., W. Ebisuzaki, J. Woollen, S. K. Yang, J. J. Hnilo, M. Fiorino, and G. L. Potter, 2002: NCEPDOE AMP-II Reanalysis (R-2). Bull. Amer. Meteorol. Soc., 83, 1631-1643, doi: 10.1175/BAMS-83-11-1631. [Link]

Kim, J. H., C. H. Ho, and P. S. Chu, 2010: Dipolar redistribution of summertime tropical cyclone genesis between the Philippine Sea and the northern South China Sea and its possible mechanisms. J. Geophys. Res., 115, D06104, doi: 10.1029/2009JD012196. [Link]

Kubota, H. and B. Wang, 2009: How much do tropical cyclones affect seasonal and interannual rainfall variability over the western North Pacific? J. Climate, 22, 5495-5510, doi: 10.1175/2009JCLI2646.1. [Link]

Kwon, M., J. G. Jhun, and K. J. Ha, 2007: Decadal change in east Asian summer monsoon circulation in the mid1990s. Geophys. Res. Lett., 34, L21706, doi: 10.1029/ 2007GL031977. [Link]

Lee, M. H., C. H. Ho, and J. H. Kim, 2010: Influence of tropical cyclone landfalls on spatiotemporal variations in typhoon season rainfall over South China. Adv. Atmos. Sci., 27, 443-454, doi: 10.1007/s00376-009-9106 -3. [Link]

Qian, W. H. and A. Qin, 2008: Precipitation division and climate shift in China from 1960 to 2000. Theor. Appl. Climatol., 93, 1-17, doi: 10.1007/s00704-007-0330-4. [Link]

Ren, F., G. Wu, W. Dong, X. Wang, Y. Wang, W. Ai, and W. Li, 2006: Changes in tropical cyclone precipitation over China. Geophys. Res. Lett., 33, L20702, doi: 10.1029/2006GL027951. [Link]

Rodgers, E. B., R. F. Adler, and H. F. Pierce, 2000: Contribution of tropical cyclones to the North Pacific climatological rainfall as observed from satellites. J. Appl. Meteorol., 39, 1658-1678, doi: 10.1175/1520-0450(20 00)039<1658:COTCTT>2.0.CO;2. [Link]

Seiki, A. and Y. N. Takayabu, 2007: Westerly wind bursts and their relationship with intraseasonal variations and ENSO. Part II: Energetics over the western and central Pacific. Mon. Weather Rev., 135, 3346-3361, doi: 10.1175/MWR3503.1. [Link]

Wu, R., Z. Wen, S. Yang, and Y. Li, 2010: An interdecadal change in southern China summer rainfall around 1992/93. J. Climate, 23, 2389-2403, doi: 10.1175/2009 JCLI3336.1. [Link]

Xie, S. P., K. Hu, J. Hafner, H. Tokinaga, Y. Du, G. Huang, and T. Sampe, 2009: Indian Ocean capacitor effect on Indo-western Pacific climate during the summer following El Niño. J. Climate, 22, 730-747, doi: 10.1175/ 2008JCLI2544.1. [Link]

Yao, C., S. Yang, W. Qian, Z. Lin, and M. Wen, 2008: Regional summer precipitation events in Asia and their changes in the past decades. J. Geophys. Res., 113, D17107, doi: 10.1029/2007JD009603. [Link]

Zhan, R., Y. Wang, and X. Lei, 2011: Contributions of ENSO and East Indian Ocean SSTA to the interannual variability of Northwest Pacific tropical cyclone frequency. J. Climate, 24, 509-521, doi: 10.1175/2010 JCLI3808.1. [Link]

Zhou, T., R. Yu, J. Zhang, H. Drange, C. Cassou, C. Deser, D. L. R. Hodson, E. Sanchez-Gomez, J. Li, N. Keenlyside, X. Xin, and Y. Okumura, 2009: Why the western Pacific subtropical high has extended westward since the late 1970s. J. Climate, 22, 2199-2215, doi: 10.1175/2008JCLI2527.1. [Link] 
Zhu, Y., H. Wang, W. Zhou, and J. Ma, 2011: Recent changes in the summer precipitation pattern in East China and the background circulation. Climate Dyn., 36, 1463 -1473, doi: 10.1007/s00382-010-0852-9. [Link] 